\title{
Composição nutricional e valores energéticos determinados com frangos de corte de coprodutos do processamento do etanol de milho
}

\author{
[Nutritional composition and energy values determined with broilers of co-products from \\ the processing of corn ethanol]
}

\author{
F.R. Santos ${ }^{1}$, M.R.S. Silva ${ }^{2}$, N.R. Oliveira $^{3}$, H.B. Santos ${ }^{3}$, D.A. Cordeiro ${ }^{4}$, C.S. Minafra ${ }^{1}$ \\ ${ }^{1}$ Instituto Federal Goiano - Rio Verde, GO \\ ${ }^{2}$ Aluna de graduação em Zootecnia do Instituto Federal Goiano - Rio Verde, GO \\ ${ }^{3}$ Alunos de pós-graduação em Zootecnia do Instituto \\ Federal Goiano - Rio Verde, GO \\ ${ }^{43}$ Aluno de pós-graduação em Zootecnia da Universidade \\ Federal de Goiás - Goiânia, GO
}

No Brasil, embora o etanol produzido pelas usinas alcooleiras seja proveniente da canade-açúcar devido ao maior rendimento de litros por hectare, atualmente, cereais como o milho têm sido alternativa para a produção do biocombustível na entressafra da cana (Milanez et al., 2014; Schone et al., 2017).

Apesar do uso dos coprodutos do etanol de grãos na nutrição animal ser comum em outros países, ainda é escassa a utilização desses ingredientes na alimentação das aves em território brasileiro. Assim, com o aumento do beneficiamento do etanol de grãos no país, tem-se estimulado o uso do óleo ácido e do DDGS de milho na alimentação animal, objetivando-se diminuir o impacto ambiental gerado por esses coprodutos e elevar a receita da indústria alcooleira.

Porém, as características nutricionais e físicas desses coprodutos podem ser afetadas por diversos fatores. Entre esses, citam-se o tipo de indústria processadora (flex ou full), a variabilidade nutricional da matéria-prima utilizada, a proporção de solúvel adicionado ao DDGS no destilador antes da secagem, a eficiência de conversão do amido em etanol, a temperatura e a duração da secagem (Martinez-Amezcua et al., 2007). Portanto, a determinação do aproveitamento nutricional de coprodutos do etanol de milho produzidos no Brasil é relevante, pois possibilitará a inclusão desses ingredientes na formulação das dietas e, com isso, elevará a sustentabilidade econômica e ambiental das cadeias avícola e alcooleira.

Objetivou-se nesta pesquisa determinar, com frangos de corte, a composição centesimal e os coeficientes de metabolização aparente da matéria seca, da proteína bruta, da energia bruta e valores de energia metabolizável aparente (EMA) e corrigida para zero balanço de nitrogênio (EMAn) dos coprodutos do etanol de milho: óleo ácido e grãos secos de destilaria com solúveis (DDGS).

O trabalho foi realizado no Setor de Avicultura do Instituto Federal Goiano, Campus Rio Verde (GO). O projeto foi aprovado pela Comissão de Ética no Uso dos Animais do IFGoiano (Ceua/IFGoiano) sob o protocolo $\mathrm{n}^{\circ} \quad 8441110317 / 2017$.

Recebido em 18 de abril de 2018

Aceito em 24 de janeiro de 2019

E-mail: fabiana.santos@ifgoiano.edu.br 
Utilizaram-se 88 pintos de corte machos, $\mathrm{Cobb}^{\circledR}$, com 24 a 32 dias de idade e peso corporal inicial igual a $1384,0 \pm 32 \mathrm{~g}$. As aves foram alojadas em gaiolas de arame galvanizado, com dimensões de $0,90 \mathrm{~m}$ x $0,60 \mathrm{~m} \times 0,45 \mathrm{~m}$. A água e a ração foram fornecidas à vontade durante todo o período experimental.

Para compor os tratamentos experimentais, uma ração referência à base de milho $\mathrm{e}$ farelo de soja foi formulada. Os níveis nutricionais calculados da ração referência foram: $22,55 \%$ de proteína bruta, 3,050Mcal/kg de EMAn, 0,81\% de cálcio, $0,39 \%$ de fósforo disponível, $0,21 \%$ de sódio, $1,26 \%$ de lisina digestível, 0,96 metionina+cistina digestível e $0,82 \%$ de treonina digestível. As rações teste foram obtidas pela substituição da ração referência por $25 \%$ do DDGS e $10 \%$ do óleo ácido de milho de acordo com a metodologia proposta por Sakomura e Rostagno (2016). Para a coleta total de excretas, as aves permaneceram em adaptação às gaiolas e às dietas experimentais por quatro dias e o período de coleta foi de mais quatro dias. Para delimitar o início e o final da coleta, utilizou-se como marcador $1 \%$ de óxido férrico na ração. Foi determinada a quantidade de ração consumida e a quantidade total de excretas produzidas.

Os coeficientes de metabolização aparente da matéria seca (CMAMS), da proteína bruta (CMAPB), da energia bruta (CMAEB) e os valores da energia metabolizável aparente (EMA) e corrigida para zero balanço de nitrogênio (EMAn) dos ingredientes foram calculados com as equações descritas por Sakomura e Rostagno (2016). A composição centesimal dos ingredientes e das excretas foi determinada segundo Silva e Queiroz (2002). A acidez e o índice de peróxidos do óleo de milho foram analisados segundo o Compêndio (2009). A energia bruta foi realizada em bomba calorimétrica adiabática Parr ${ }^{\circledR}$, no Laboratório de Nutrição Animal da Unesp, Campus Jaboticabal.

O delineamento experimental utilizado foi o inteiramente ao acaso, com três tratamentos e sete repetições de quatro aves cada. As médias \pm desvio-padrão foram apresentadas e os dados foram submetidos à análise de variância por meio do programa SISVAR. O coproduto utilizado nesta pesquisa apresenta $42 \%$ de proteína bruta e é considerado um DDGS high protein (Tab. 1). Quando a composição do DDGS atinge proporções acima de $39 \%$ de proteína bruta, é considerada como de alta proteína (DDGS high protein); quando são encontrados teores abaixo de $38 \%$, tem-se o DDGS de baixa gordura (DDGS low-fat). O DDGS high protein é produzido quando o farelo e o gérmen são retirados, o endosperma é direcionado para fermentação e produção do etanol, porém esse coproduto contém menor teor lipídico (Singh et al., 2005).

Os coeficientes de metabolização aparente (CMA) da EB, MS e PB do DDGS foram iguais a 50,8; 49,11 e 60,23\%, respectivamente (Tab. 2). O elevado teor de polissacarídeos não amiláceos (PNAs) do DDGS $(53,34 \%$ de FDN e $11,3 \%$ de FDA) é fator limitante na digestibilidade de nutrientes para aves (Opalinski et al., 2006). Porém, esse valor é superior aos CMA da MS e da PB $(47,19 \%$ e 46,38\%, respectivamente), determinados com o farelo de soja segundo Sakomura et al. (2004) e Santos et al. (2015). 
Tabela 1. Composição centesimal na matéria natural dos coprodutos de etanol de milho

\begin{tabular}{lcc} 
& DDGS de milho $^{1}$ & Óleo ácido de milho $^{1}$ \\
\hline Matéria seca (\%) & $90,22 \pm 1,35$ & $99,68 \pm 0,98$ \\
Proteína bruta (\%) & $42,06 \pm 0,97 \%$ & - \\
Extrato etéreo (\%) & $3,21 \pm 0,55 \%$ & - \\
Cinzas (\%) & $2,35 \pm 0,15$ & - \\
FDN (\%) & $53,34 \pm 1,88 \%$ & - \\
FDA (\%) & $11,13 \pm 0,66$ & - \\
Energia bruta, kcal/kg & $4206 \pm 34$ & $9602,5 \pm 54$ \\
Índice de peróxidos & - & $20,75 \pm 0,43$ \\
Acidez (\%) & - & $9,28 \pm 0,85$ \\
\hline
\end{tabular}

${ }^{\mathrm{T}}$ Média \pm desvio-padrão; ${ }^{2}$ fibra em detergente neutro; ${ }^{3}$ fibra em detergente ácido.

Tabela 2. Coeficientes de metabolização aparente da matéria seca (CMAMS, \%), da proteína bruta (CMAPB, \%), da energia bruta (CMAEB, \%) e valores de energia metabolizável aparente (EMA) e corrigida para balanço de nitrogênio igual a zero (EMAn) na matéria natural (MN) e na matéria seca (MS) dos coprodutos de etanol de milho determinada com frangos de 24 a 32 dias de idade

\begin{tabular}{lcc}
\hline Dados na matéria seca & & \\
\hline & DDGS $^{1}$ & Óleo ácido de milho $^{1}$ \\
\hline EMA, kcal/kg & $2662,8 \pm 77,3$ & $7957,9 \pm 25,7$ \\
EMAn, $\mathrm{kcal} / \mathrm{kg}$ & $2614,3 \pm 77,3$ & $7878,5 \pm 23,4$ \\
CMAMS, \% & & $88,45 \pm 3,46$ \\
CMAPB, \% & $49,11 \pm 1,55$ & - \\
CMAEB, \% & $60,23 \pm 2,94$ & $82,67 \pm 0,27$ \\
Dados na matéria natural & $50,80 \pm 1,47$ & \\
EMA, kcal/kg & & $7938,4 \pm 25,6$ \\
EMAn, kcal/kg & $2438,0 \pm 70,8$ & $7859,2 \pm 23,3$ \\
\hline
\end{tabular}

${ }^{1}$ Médias \pm desvio-padrão obtidas com sete repetições de quatro aves cada.

O DDGS de milho avaliado neste estudo apresentou, na base natural, valor de EMAn $(2393,5 \mathrm{kcal} / \mathrm{kg})$ condizente aos observados na literatura. Guney et al. (2013) avaliaram a EMAn de cinco amostras diferentes de DDGS da indústria do etanol e encontraram valores energéticos variando entre 2255 e $2944 \mathrm{kcal} / \mathrm{kg}$. Essa variação na composição energética desse coproduto está ligada ao conteúdo de extrato etéreo da amostra, de proteína, de amido, assim como os níveis de PNAs.
O óleo ácido de milho apresentou CMAMS e EMAn iguais a $88,45 \%$ e $7859,2 \mathrm{kcal} / \mathrm{kg}$, respectivamente. Esse valor é inferior à EMAn do óleo de milho $(8773 \mathrm{kcal} / \mathrm{kg})$ apresentada pelas Tabelas Brasileiras, (Rostagno, 2017), porém é superior aos valores de EMAn do óleo ácido de soja obtidos com pintos $(7.338 \mathrm{kcal} / \mathrm{kg})$ por Freitas et al. (2005). O menor valor nutricional de óleos com níveis elevados de acidez é justificado pelo alto conteúdo de ácidos graxos livres nesses ingredientes. A 
presença de ácidos graxos esterificados com glicerol é considerada importante para a formação de micelas no processo de emulsificação e melhoria da absorção das gorduras. Nesse contexto, a menor proporção de gordura total na forma de triglicerídeos e a maior proporção de ácidos graxos livres podem ter prejudicado os mecanismos de ativação da secreção de bile e formação das micelas, reduzindo a digestibilidade e a disponibilidade de energia do óleo ácido de milho, conforme verificado com o óleo ácido de soja por Freitas et al. (2005).
Em suma, considerando-se o menor preço de mercado, os valores nutricionais e $\mathrm{o}$ aproveitamento energético dos ingredientes estudados, conclui-se que o óleo ácido e o DDGS de milho são alternativas viáveis aos ingredientes tradicionais na composição de dietas para aves. Para garantir a manutenção do desempenho dos animais, pesquisas para determinar os níveis de inclusão desses coprodutos na formulação de rações para frangos de corte devem ser realizadas.

Palavras-chave: aproveitamento nutricional, biocombustível, DDGS, óleo ácido

\begin{abstract}
It was determined by the total collection of excreta method, with broilers from 22 to 32 days of age, the coefficients of apparent metabolism of dry matter, crude protein and crude energy and apparent metabolizable energy corrected for zero nitrogen balance (AMEn) of the ethanol coproducts of corn: acid oil and dried distillery grains with soluble (DDGS). The DDGS and corn acid oil presented nutritional metabolization coefficients ranging from 43 to $83 \%$ and AMEn equal 2393.5 and $7859.2 \mathrm{kcal} / \mathrm{kg}$ respectively, and may be food alternatives to soybean meal and soybean oil.
\end{abstract}

Keywords: nutritional use, biofuel, DDGS, acid oil

\section{REFERÊNCIAS}

COMPÊNDIO brasileiro de nutrição animal. 3.ed. São Paulo: Sindicato Nacional da Indústria de Alimentação Animal, 2009. 204p.

FREITAS, E.R.; SAKOMURA, N.K.; NEME, R. et al. Valor energético do óleo ácido de soja para aves. Pesqui. Agropecu. Bras.,v.40, p.241-246, 2005.

GUNEY, A.C.; SHIM, M.Y.; BATAL, A.B. et al. Effect of feeding low-oil distillers dried grains with solubles on the performance of broilers. Poult. Sci., v.92, p.2070-2076, 2013.

MARTINEZ-AMEZCUA, C.; PARSONS, C.M.; SINGH, V. et al. Nutritional characteristics of corn distillers dried grains with solubles as affected by the amounts of grains versus solubles and different processing techniques. Poult. Sci., v.86, p.2624-2630, 2007.
MILANEZ, A.Y.; NIKO, D.; VALENTE, M.S. et al. A produção de etanol pela integração do milho-safrinha às usinas de cana-de-açúcar: avaliação ambiental, econômica e sugestões de política. Rev. BNDES, v.41, p.147-208, 2014.

OPALINSKI, M.; MAIORKA, A.; CUNHA, F. et al. Adição de níveis crescentes de complexo enzimático em rações com soja integral desativada para frangos de corte. Arch. Vet. Sci., v.11, p.31-35, 2006.

ROSTAGNO, H.S.; ALBINO, L.F.T.; DONZELE, J.L. et al. Tabelas brasileiras para aves e suínos - composição e alimentos e exigências nutricionais. 3.ed. Viçosa: UFV, 2017. 252p.

SAKOMURA, N.K.; DEL BIANCHI, M.; PIZAURO JR, J.M. et al. Effect of age on enzyme activity and nutrients digestibility for broilers fed soybean meal and full fat soybean. Rev. Bras. Zootec., v.33, p.924-935, 2004. 
SAKOMURA, N.K.; ROSTAGNO, H.S. Métodos de pesquisa em nutrição de monogástricos. 2.ed. Jaboticabal: Funep, 2016. $283 \mathrm{p}$.

SANTOS, F.R., STRINGHINI, J.H., OLIVEIRA, P.R. et al. Values of metabolizable energy and metabolization of nutrients for slowand fast-growing birds at different ages. Rev. Bras. Cienc. Avic., v.17, p.517-522, 2015.

SCHONE, R.A.; NUNES, R.V.; FRANK, R. et al. Resíduo seco de destilaria com solúveis (DDGS) na alimentação de frangos de corte (2242 dias). Rev. Cienc. Agron., v.48, p.548-557, 2017.
SILVA, D.J.; QUEIROZ, A.C. Análise de alimentos (métodos químicos e biológicos). Viçosa: UFV, 2002. 235p

SING, V.; JOHSNSTON, D.B.; NAIDU, K. et al. Comparison of modified dry-grinding corn process for fermentation characteristics and DDGS composition. Cereal Chem., v.82, p.187190, 2005. 